\title{
Effects Supervised Versus Home-Based Rehabilitation on Functional Outcome after Surgical Fixation of Distal Humerus Fractures
}

\author{
HAROON-UR-REHMAN GILLANI ${ }^{1}$, MUHAMMAD UMAR HABIB ${ }^{2}$, DANISH HASSAN ${ }^{3}$, SYED MUHAMMAD SHAH ${ }^{4}$ \\ ${ }^{1}$ Associate Professor Orthopedic Surgery, Sahiwal Medical College, Sahiwal \\ ${ }^{2}$ Sports and Exercise Medicine, Queens Medical Centre, University of Nottingham, UK \\ ${ }^{3}$ Assistant Professor, Riphah College of Rehabilitation \& Allied Health Sciences, Riphah International University \\ ${ }^{4}$ Senior Lecturer, University Institute of Physical Therapy, The University of Lahore \\ Correspondence to Dr.Danish Hassan, Email: danish.hassan009@gmail.com Contact :0345-7946009
}

\begin{abstract}
Background: The focus for early postoperative motion in stable fixation is aimed at good restoration of joint anatomy in relation to movements, strength, and joint play and to compare the functional outcomes after the surgical repair of distal humerus fractures in contrast with supervised and home-based rehabilitation.

Aim: To provide guidelines to effectively manage the post-operative functional complications.

Method: Sixty-four patients with the distal humerus fractures were treated surgically, participated in the study at the mean follow up of 6 months. Mayo Elbow Performance Score (MEPS), Disabilities of the Arm shoulder and Hand (DASH), Visual Analogue Scale and Goniometer, radiographic evaluation was done to assess outcomes at baseline ( $2^{\text {nd }}$ week after cast removal), $10^{\text {th }}$ week $\& 6^{\text {th }}$ month post-operative.

Results: Among 60 patients, average MEPS, DASH, Arc of motion was significantly better in supervised rehabilitation group in contrast with home-based rehabilitation group $(\mathrm{p}=0.00, \mathrm{Cl} 95 \%)$. Average healing time observed on radiographs was $10-12$ weeks. The overall complication rate was only $4.7 \%$, while most of the minor complications resolved without any intervention.

Conclusions: Outcomes of distal humerus fractures were good to excellent in both groups, whereas supervised rehabilitation provided better outcomes in context with ranger of motion, mobility, and functionality.

Keywords: Olecranon Osteotomy, Elbow Fractures, Functional outcome, Elbow Rehabilitation
\end{abstract}

\section{INTRODUCTION}

Elbow joint comprised of complicated anatomy, providing ${ }^{1}$. Nearly $7 \%$ of the adults accounted for elbow fractureswith the prevalence of distal humerus fracture accounted for $30 \% \%^{2,3}$. Occurrence of distal humerus fractures showed bimodal distribution in relation to age, with pattern of high energy among adults and teenagers, and osteoporosis with less energy blow in the elderly ${ }^{4}$

For most of the displaced fractures, open reduction with internal fixation is most appropriate method with aim to restore the fractured segment anatomically providing appropriate stability and is reported to have better functional ${ }^{5}$. Surgical management of these fractures is preferable due to complex anatomy and moreover, braces or casts alone failed to restrict segment and provide unsatisfactory stability. However, post-operative casts requires longer period of immobility and rest which eventually lead to contractures and stiffness around the elbow region further limiting the activity ${ }^{6}$. However, most of daily activities required 30 to 130 degrees of elbow flexion $n^{7,8}$ and almost 100 degrees of rotation with both supination and pronation contribute equally ${ }^{9}$. Shoulder abduction compensates for any loss of pronation, but no secondary mechanism exists for compensation of any supination loss $^{10}$.

The focus for early postoperative motion in stable fixation is aimed at good restoration of joint anatomy in relation to movements, strength and joint play. But this is difficult to achieve which can lead to complications and unsatisfactory results among $15 \%$ of individuals ${ }^{11-13}$.

So, the present study focused on the functional outcomes after the plate fixation of distal humerus fractures, aiming at early mobilization, adhesions preventions and joint play restoration and contrast the supervised post-operative rehabilitation regimen with the home-basedexercise program in the form of visually assisted exercises diagrams to evaluate and distinguish satisfactory results and movement dysfunctions.

\section{METHODOLOGY}

Patients Selection: This study recruited 60 participants after permission from Ethical Committee, who sustain distal humerus fractures and were operated surgically at Department of Orthopedics, Sahiwal Medical College, Pakistan between 2017

Received on 15-05-2021

Accepted on 25-09-2021 and 2020. Any patient who sustained isolated, closed, or open, displaced intra-condylar or intra-articular fracture of distal humerus was included in the study. Patients with involvement of proximal radius or ulna, skeletally immature, an ipsilateral or contralateral upper-extremity injury and preexisting musculoskeletal condition were excluded.

Surgical Approach: Patients were classified according to American Orthopedics (AO) classification into C1, C2 and C3. All the patients were operated using medial or lateral plating with appropriate surgical approach with regards to segment involved and feasibility of anatomical reconstruction like olecranon osteotomy for intra-articular fracture.

Post-operative Care: All the patients were monitored for signs of infection and appropriate care was initiated with antibiotics and NSAIDs. After the careful examination and X-ray, cast was removed partially at $2^{\text {nd }}$ week and patient was allowed to do guided activities. Range of motion (ROM) exercises of hand and shoulder was started earlier at $1^{\text {st }}$ day post-operatively.

Patients Grouping: An external assistant randomly allocated the patients to either the home-based rehabilitation or supervised rehabilitation group using a computer-generated random sequence (randomized.com). Patients were divided into two groups:

Home-Based Rehabilitation Group: After the partial removal of cast at post-operative $2^{\text {nd }}$ week, patient was taught about selfmobilization of elbow using any belt, self-distraction technique with cotton roll while monitoring the pain, diagrams of exercises showing active and passive movements and gentle stretching with protocols of duration, intensity, and frequency.

Supervised Rehabilitation Group: The treatment group received gentle elbow mobilization and distraction, active and passive ROM and stretching. Elbow distraction: Patient was comfortable in lying supine. The Clinician apply a traction belt around the proximal part of forearm with elbow flexed to 90 degrees. With the scooping of both hands of clinician along with grasping of belt, a gentle traction was applied and sustained for 20 seconds. Shoulders of clinicians are used to provide stability to distal forearm. Elbow Mobilization with Movement: With the patient lying supine on couch, a mobilization belt was placed around the proximal part of forearm and surrounded the pelvis of clinician at the same level. One hand of therapist stabilizes the distal part of humerus while the other provide stability to distal forearm. A gliding force was applied in lateral direction and patient was instructed to actively flex and extend his/her elbows. 
Data Collection: A blind assessor assessed the patient at baseline usually after the removal of cast at $2^{\text {nd }}$ week postoperatively to check stability and take baseline measurements, at $10^{\text {th }}$ week post-operative after regular exercises and physiotherapy, and at 6 months post-operatively. Signed informed consent was taken and protocol of the study was approved form Ethical Review Committee of Sahiwal Medical College \& Allied Hospital, Sahiwal.

Outcomes: Visual analogue scale (VAS) was used to quantify pain subjectively. Mayo Elbow performance scale (MEPS), The Disabilities of Shoulder Arm and Hand (DASH) quantify the functional outcomes. Goniometry examined the ROM of elbow flexion and elbow extension.

\begin{tabular}{|c|c|c|}
\hline & $\begin{array}{l}\text { Supervised } \\
\text { Rehabilitation Group } \\
\text { Baseline Data collection } \\
\text { at 2nd Week after } \\
\text { removal of cast }\end{array}$ & $\begin{array}{l}\text { Home } \\
\text { Rehabilitation Group } \\
\text { Baseline Data collection } \\
\text { at 2nd Week after } \\
\text { removal of cast }\end{array}$ \\
\hline $\begin{array}{l}\text { Post- } \\
\text { operative } \\
\text { Week } 3^{\text {rd }} \\
\text { to } \\
10^{\text {th }}\end{array}$ & $\begin{array}{l}\text { Heating for } 10 \text { minutes } \times \\
\text { daily } \\
\text { Elbow Distraction } \times 20 \text { Sec } \\
\times 3 \text { Times } \times \text { Twice Weekly } \\
\text { Elbow Mobilization with } \\
\text { Movement } \times 3-6 \text { Times } \times \\
\text { Twice Weekly } \\
\text { Active ROM (In clinic and } \\
\text { Home Guided) } 15 \text { minutes } \\
\times \text { Daily } \\
\text { Passive ROM (In Clinic } \\
\text { and Home Guided) } 15 \\
\text { minutes } \times \text { daily }\end{array}$ & 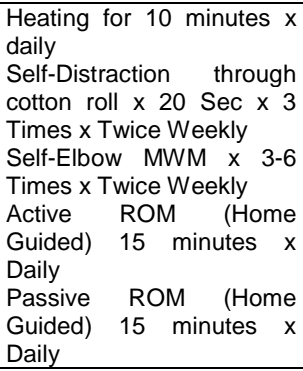 \\
\hline Follow up & $\begin{array}{l}\text { Home Based Active and } \\
\text { Functional Exercises }\end{array}$ & $\begin{array}{l}\text { Home Based Active and } \\
\text { Functional Exercises }\end{array}$ \\
\hline
\end{tabular}

Statistical Analysis: The data was analyzed using SPSS v 27. The normality of the data was assessed using Shapiro-Wilks test of normality and uniformity, based on which parametric or nonparametric test were applied to determine across the group difference in two groups. Independent sample $T$ test was applied to determine any significant difference across the two groups. A difference with $p$ value less than 0.05 was considered as significant.

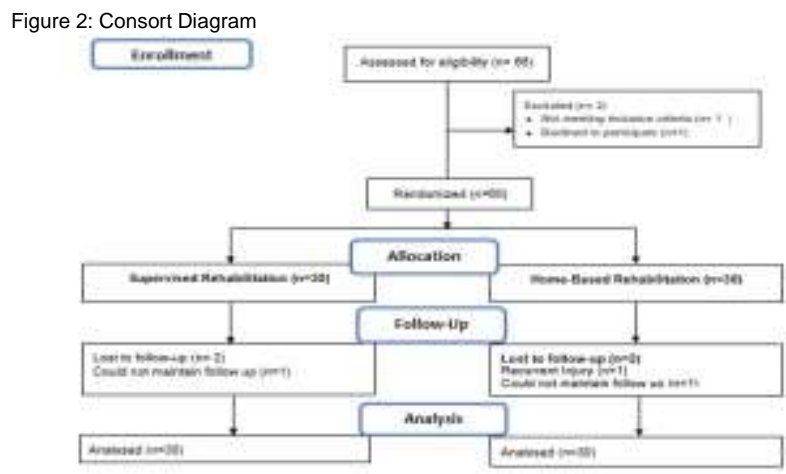

\section{RESULTS}

Table 2: Functional related outcomes and their significance

\begin{tabular}{|c|c|c|c|c|c|c|}
\hline & & Supervised Rehabilitation & Home-Based Rehabilitation & Mean Difference & $95 \% \mathrm{Cl}$ & $\mathbf{P}$ \\
\hline \multirow[t]{3}{*}{ VAS } & Baseline & $5.80+2.73$ & $6.20+2.99$ & -0.4 & $-1.88,1.08$ & 0.13 \\
\hline & At $10^{\text {th }}$ week & $1.33+2.05$ & $3.20+2.26$ & -1.86 & $-3.11,-0.62$ & 0.04 \\
\hline & At 6 Months & $0.66+0.36$ & $0.66+0.36$ & 0 & $1.88,0.18$ & 1 \\
\hline \multirow[t]{3}{*}{ Total MEPS } & Baseline & $40.46+11.49$ & $38.00+13.49$ & 2.46 & $-4.01,8.94$ & 0.44 \\
\hline & At $10^{\text {th }}$ week & $87.50+6.79$ & $68.01+17.25$ & 19.50 & $12.64,26.35$ & 0.00 \\
\hline & At $6^{\text {th }}$ Month & $96.50+4.93$ & $83.33+10.23$ & 12.16 & $9.07,17.25$ & 0.00 \\
\hline \multirow{3}{*}{$\begin{array}{l}\text { DASH } \\
\text { Score }\end{array}$} & Baseline & $90.26+2.78$ & $91.16+2.32$ & -0.9 & $-2.22,0.42$ & 0.18 \\
\hline & At $10^{\text {th }}$ week & $28.56+3.71$ & $44.34+8.00$ & -15.78 & $-19.03,-12.53$ & 0.00 \\
\hline & At $6^{\text {th }}$ Month & $17.65+2.41$ & $31.25+7.05$ & -13.60 & $-16.36,-10.83$ & 0.00 \\
\hline \multirow{3}{*}{$\begin{array}{l}\text { Elbow Arc of Motion } \\
\text { (flexion-extension) }\end{array}$} & Baseline & $10.01+3.05$ & $11.33+3.55$ & -1.33 & $-3.04,0.37$ & 0.12 \\
\hline & At $10^{\text {th }}$ week & $124.36+7.34$ & $107.46+10.70$ & 17.23 & $2.36,12.47$ & 0.00 \\
\hline & At $6^{\text {th }}$ Month & $127.46+6.04$ & $112.03+10.72$ & 15.43 & $10.93,19.93$ & 0.00 \\
\hline
\end{tabular}

Test of normality was confirmed and parametric test (independent sample t-test was applied to check the difference between two groups. P value less than 0.05 considered to give

The total 60 patient, 30 in each group who sustained the distal humerus fractures were included in the study with the average of 36 (SD 8, Range 55-20) years of age and majority were males (72\%). Patients were classified according to American Orthopedic (AO) classification system into C1 $(n=9), C 2(n=16)$, and C3 $(n=5)$, and theaverage healing time after surgery evaluated by radiographs and clinical assessment were about 9-12 weeks. There were only three exceptions about healing with two patients had wound complication and one patient had recurrent trauma

Figure 3: Comparison of MEPS among both groups

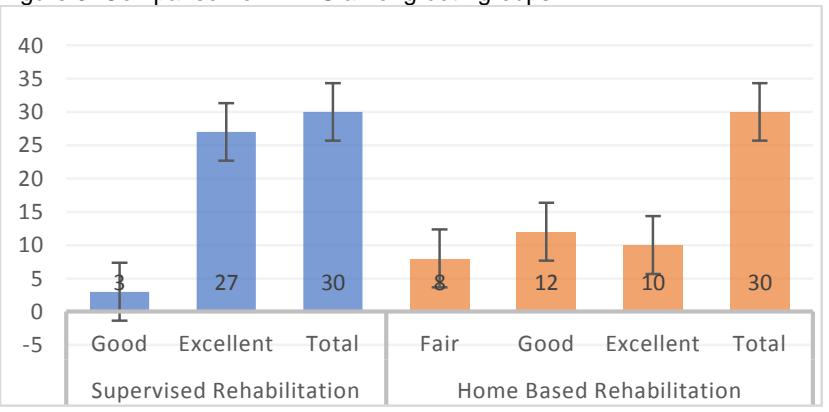

Table 1: Demographics and patients related outcomes

\begin{tabular}{|c|c|c|c|}
\hline Variables & & $\begin{array}{l}\text { Supervised } \\
\text { Rehabilitation }\end{array}$ & $\begin{array}{l}\text { Home Based } \\
\text { Rehabilitation }\end{array}$ \\
\hline $\mathrm{N}$ & & 30 & 30 \\
\hline Age (Years) & & 34 (SD 8) & 38 (SD 8) \\
\hline \multirow[t]{2}{*}{ Gender } & Male & 22 & 21 \\
\hline & Female & 8 & 9 \\
\hline \multirow{3}{*}{$\begin{array}{l}\text { AO Fracture } \\
\text { Type }\end{array}$} & C1 & 9 & 10 \\
\hline & $\mathrm{C} 2$ & 16 & 14 \\
\hline & C3 & 5 & 6 \\
\hline \multirow[t]{2}{*}{ Side of Injury } & Right & 19 & 18 \\
\hline & Left & 11 & 12 \\
\hline \multicolumn{2}{|c|}{$\begin{array}{l}\text { Average bone healing time } \\
\text { (weeks) }\end{array}$} & 9.66 (SD 1.37) & 10.1 (SD 1.65) \\
\hline \multirow[t]{2}{*}{ Complications } & Wound & 1 & 1 \\
\hline & $\begin{array}{l}\text { Mal or Non- } \\
\text { Union }\end{array}$ & 0 & 1 \\
\hline
\end{tabular}

Patients who were included in the spervised rehabilitation groups showed overall greater MEPS score, with 27 patients scored as excellent and 3 cases were catagorized as good, with no fair or poor reporting. In the home based rehabilitation group, participants showed comparitively less improvement with only 10 patients with the excellent score (Figure 3).

The MEPS score was measured to classify the elbow function. An independent sample T-test was conducted to compare the average MEPS among both groups. There was significant difference in MEPS at $6^{\text {th }}$ month follow up for supervised rehabilitation $(\mathrm{M}=96.50, \mathrm{SD}=4.93)$ and home-based rehabilitation $(\mathrm{M}=83.33, \mathrm{SD}=10.23)$ with $\mathrm{p}$ value of 0.00 (two-tailed). 
Significant difference between two groups also observed after 8 weeks of rehabilitation (post-operative $10^{\text {th }}$ week) with $p=0.00$. However, patient in home-based rehabilitation obtained an excellent/ good MEPS among $66 \%$ of the cases although this is less than the supervised rehabilitation group. Similar results were obtained in DASH score and elbow arc of motion as the independent sample t-test showed significant difference among both groups. Mean difference of $\mathrm{DASH}=15.78$ at $10^{\text {th }}$ week, $\mathrm{DASH}=13.60, \mathrm{p}=0.00$, elbow arc of motion (difference in elbow flexion and extension) was 17.23 at $10^{\text {th }}$ week, 15.43 at 6 months, $\mathrm{p}=0.00$ was calculated (Table 2 ).

\section{DISCUSSION}

This study compared the functional outcome of surgically operated distal humerus fractures in contrast with home-based exercise program done by patient after specified instructions provided in the leaflet, and supervised rehabilitation provided by the physiotherapist. Exercise program was equally designed for both groups in term of technique, intensity, frequency, and type of exercises. After analyzing 60 cases of distal humerus fractures, supervised rehabilitation would confer superior functional outcomes in contrast with home-based rehabilitation. However, both groups showed significant improvement in term of functional outcomes with an excellent/good MEPS in majority of cases.

The study appends four different variables in terms of functional outcomes in both post-operative groups with the fracture of distal humerus. In recent study, average MEPS was reported $96.50(S D=4.93)$ in supervised rehabilitation group in contrast with 83.33 (SD 10.23). There was significant result in MEPS $(p=0.00$, $\mathrm{Cl}, 95 \%$ ) among both groups and this is because the supervised rehabilitation more efficiently breaks the adhesion, maintained joint play, and restrict the joint stiffness. However, patient with homebased program also provide satisfactory results and supported by the research. Vivek Trikha et al, studied the functional outcome of extra-articular distal humerus fracture and concluded that 34 patients $(94.44 \%)$ had complete union within 3 months. Average MEPS was $90.8+9.9$ with average follow up of 1 year without proper physiotherapy ${ }^{14}$. So, our study not only decreases the average follow up period, but also reported increase MEPS score.

In our study, mean DASH score was comparatively more in both treatment as well as control group in comparison with previous studies. It was $17.65 \quad(\mathrm{SD}=5.4)$ in the supervised rehabilitation group and $31.25(\mathrm{SD}=7.05)$ in home-based group. Kanthan Theivendran et al studied the functional outcome after internal fixation using precontoured anatomic plates. The mean DASH score was 46.1 , grip strength was $56 \%$ of the uninjured side, and the mean MEPS score was 72.3 with average 24 months follow up ${ }^{15}$. Available studies on recovery after fracture of the elbow joint focus on the cause and treatment of stiffness of the joint but the recovery of the range of motion of the elbow joint after a simple elbow fracture has not yet included in the literature ${ }^{16}$. Our study shows similar results on VAS among both groups using postoperative rehabilitation regimen. In term of elbow arc of motion, supervised rehabilitation group was reported $127.46(\mathrm{SD}=$ 8.9) while $112.03(\mathrm{SD}=9.3)$ was in home-based group. Our study also focused on early mobilization after 2 weeks post-operatively which resulted in no implant failure or non-union reported.

In spite of leaving search terms broad and employing two highly utilized databases, the possibility of missing studies on distal humerus fractures still existed ${ }^{17}$. On the other hand, weak obedience with follow-up and physical therapy appointments was fairly common, leading possibly to the limitation of motion range. The reasons for insufficient enforcement include other medical problems and overall health issues, lack of transportation access as well as physical therapy procedure difficulties ${ }^{18}$.

Overall, our study supports no more variability in the findings obtained from the patients who undergone treatment and the others who did not in some variables. While treatment sessions are only better in improving the range of motion and functionality of the patients.

\section{CONLCUSION}

Supervised and home-based exercises were equally effective in reducing pain, disability and improving elbow function after plate fixation of distal hummers fracture. Supervised exercise was better in reducing disability and improving elbow function clinically as compared to home-based rehabilitation. The variability found in the reported outcome measures apparently makes it a problem for the orthopedic surgeons to decide about which current treatment modalities would be better for acute distal humerus fractures but in our study, there are no more complications for the surgeons to decide either the treatment modalities would be better or the home plan while keeping the ROM and functionality in mind which is a major point to be clear about in different major treatment centers.

\section{Conflict of interest: Nil}

\section{REFERENCES}

1. O'Driscoll SW, Jupiter JB, King GJ, Hotchkiss RN, Morrey BF. The unstable elbow. Instructional course lectures. 2001;50:89-102.

2. Anglen J. Distal humerus fractures. The Journal of the American Academy of Orthopaedic Surgeons. 2005;13(5):291-7.

3. Palvanen $M$, Kannus $P$, Niemi $S$, Parkkari J. Secular trends in the osteoporotic fractures of the distal humerus in elderly women. European journal of epidemiology. 1998;14(2):159-64.

4. Robinson CM, Hill RM, Jacobs N, Dall G, Court-Brown CM. Adult distal humeral metaphyseal fractures: epidemiology and results of treatment. Journal of orthopaedic trauma. 2003;17(1):38-47.

5. Kwasny $\mathrm{O}$, Maier R. [The significance of nerve damage in upper arm fractures]. Der Unfallchirurg. 1991:94(9):461-7.

6. Marsh JL, Slongo TF, Agel J, Broderick JS, Creevey W, DeCoster TA, et al. Fracture and dislocation classification compendium - 2007: Orthopaedic Trauma Association classification, database and outcomes committee. Journal of orthopaedic trauma. 2007;21(10 Suppl):S1-133.

7. Boone DC, Azen SP. Normal range of motion of joints in male subjects. The Journal of bone and joint surgery American volume. 1979;61(5):756-9.

8. Morrey BF, Chao EY. Passive motion of the elbow joint. The Journal of bone and joint surgery American volume. 1976;58(4):501-8

9. An KN, Morrey BF, Chao EY. The effect of partial removal of proximal ulna on elbow constraint. Clinical orthopaedics and related research. 1986(209):270-9

10. Kapandji A. Biomechanics of pronation and supination of the forearm. Hand clinics. 2001;17(1):111-22, vii.

11. Ring D, Jupiter JB. Fractures of the distal humerus. The Orthopedic clinics of North America. 2000;31(1):103-13.

12. Sodergard J, Sandelin J, Bostman O. Postoperative complications of distal humeral fractures. 27/96 adults followed up for $6(2-10)$ years. Acta orthopaedica Scandinavica. 1992;63(1):85-9.

13. Amis AA, Hughes SJ, Miller JH, Wright V. A functional study of the rheumatoid elbow. Rheumatology and rehabilitation. 1982;21(3):151-7.

14. Trikha V, Agrawal P, Das S, Gaba S, Kumar A. Functional outcome of extra-articular distal humerus fracture fixation using a single locking plate: A retrospective study. Journal of orthopaedic surgery (Hong Kong). 2017;25(3):2309499017727948.

15. Theivendran K, Duggan PJ, Deshmukh SC. Surgical treatment of complex distal humeral fractures: Functional outcome after internal fixation using precontoured anatomic plates. Journal of Shoulder and Elbow Surgery. 2010;19(4):524-32.

16. Wang Y-L, Chang W-N, Hsu C-J, Sun S-F, Wang J-L, Wong C-YJJoot. The recovery of elbow range of motion after treatment of supracondylar and lateral condylar fractures of the distal humerus in children. 2009;23(2):120-5.

17. Hohmann E, Tetsworth K, Bryant AJKs, sports traumatology, arthroscopy. Physiotherapy-guided versus home-based, unsupervised rehabilitation in isolated anterior cruciate injuries following surgical reconstruction. 2011;19(7):1158-67.

18. Huang JI, Paczas M, Hoyen HA, Vallier HAJJoot. Functional outcome after open reduction internal fixation of intra-articular fractures of the distal humerus in the elderly. 2011;25(5):259-65 